\title{
REDES ESCALARES EN LA CONSTRUCCIÓN DE LOS PATRIMONIOS DE LA HUMANIDAD. EL CASO DE LA PATRIMONIALIZACIÓN DE LA QUEBRADA DE HUMAHUACA (JUJUY, ARGENTINA)*
}

\author{
Hortensia Castro** \& Perla Zusman***
}

\section{RESUMEN:}

El objetivo del trabajo es analizar el proceso de constitución de objetos y lugares como Patrimonio de la Humanidad, una figura que ha implementado la UNESCO, el principal organismo que interviene en los procesos de patrimonialización a nivel mundial. Nuestro argumento central es que el proceso de patrimonialización involucra la construcción de una red escalar en la que participan diferentes sujetos, situados en distintos lugares, con distintos intereses y objetivos. El estudio de la declaración de la Quebrada de Humahuaca (Jujuy, Argentina) como Patrimonio de la Humanidad nos permitió comprender que ello sólo fue posible a través de negociaciones en que prácticas culturales globales se tornaron locales y prácticas culturales locales se tornaron globales.

\section{PALAVRAS CLAVES:}

Patrimonio de la Humanidad, redes escalares, global, local, Quebrada de Humahuaca.

\section{ABSTRACT:}

The aim of this paper is to analyze the process of constitution of objects and places as World Human Heritage, a figure created by UNESCO, the main agency that takes over heritage processes at world level. Our central argument is that heritage processes involves the construction of network scales in which different subjects with different interests and aims, situated in different places participate. The study of the constitution of Quebrada de Humahuaca (Jujuy, Argentina) as World Human Heritage let us understand that this heritage process was only possible through negotiations in which global cultural practices become local and local cultural practices become global.

\section{KEY-WORDS:}

Humanity World Heritage, , scales networks, global, local, Quebrada de Humahuaca

\section{Procesos de patrimonialización y relaciones escalares}

En los últimos años se asiste a un gran incremento en las propuestas de constitución de lugares y objetos en patrimonio histórico, cultural y natural, fundamentalmente bajo el auspicio y fomento de la UNESCO. En efecto, desde comienzos de la década del noventa el número de bienes patrimonializados por esa institución casi se ha triplicado: de 282, a fines de la década del ochenta, a 754, en el año 2004 (UNESCO, 2004).

Al mismo tiempo, se registra un aumento en el interés por analizar los componentes, alcances y efectos de estas propuestas y procesos de patrimonialización. De hecho, dentro de la bibliografía es posible distinguir dos corrientes y líneas de trabajo. La primera, que parte de la incuestionabilidad

\footnotetext{
*Versión ampliada y modificada de la ponencia presentada en el Congreso Internacional Políticas Culturales e Integración Regional. Facultad de Filosofía y Letras, Universidad de Buenos Aires. Buenos Aires, 30 de marzo al 02 de abril de 2004.

**Instituto y Departamento de Geografía, Facultad de Filosofía y Letras, Universidad de Buenos Aires. E-mail: hcastro@filo.uba.ar

***CONICET - Instituto de Geografía, Universidad de Buenos Aires. E-mail: perlazusman@yahoo.es
} 
del requerimiento de patrimonializar ciertos bienes o lugares, focaliza su interés en las estrategias para lograr consensos y garantizar la gestión (BALLART HERNÁNDEZ y JUAN I TRESSERRAS, 2001); dentro de esta línea encontramos, por ejemplo, aquellos estudios que consideran de importancia la participación social, tanto en los procesos de patrimonialización como en la definición de sus usos (GARCÍA CANCLINI, 1999; NIGRO, 2002). La segunda línea de trabajo busca desconstruir el concepto de patrimonio al considerar que los procesos de patrimonialización suponen la presencia de un comité de expertos que "seleccionan" y "activan" un conjunto de atributos en ciertos monumentos, construcciones y lugares (PRATS, 1998; GRAHAM, ASHWORTH, TUNBRIDGE, 2000); además, entiende que tales atributos estarían asociados a ciertas ideas de naturaleza, historia y genialidad que poseen aquellos expertos, portavoces de valores hegemónicos (PRATS, 1998).

Siguiendo esta segunda línea de análisis de la cuestión, nuestro argumento central es que el proceso de patrimonialización de un objeto o un lugar involucra la construcción de una red escalar en que participan diferentes sujetos con distintos intereses y objetivos. Así, se observa que algunos sujetos, que actúan a nivel local, pueden asociarse con otros que tienen su campo de acción a nivel nacional o global para conseguir la patrimonialización de ciertos objetos o lugares. En particular, éste es el eje en el cual centraremos nuestra atención: las formas en que se van tejiendo redes escalares con el objetivo de constituir lo patrimonial.

En este sentido, nuestra concepción de escala se aleja de su visión cartográfica o metodológica para enfatizar el proceso de construcción social y, más precisamente, política de la misma. Esto quiere decir que es desde los procesos sociales, económicos y políticos que se definen los diferentes niveles de actuación, y que esta diferenciación y jerarquización escalar es un requisito para que dichos procesos se lleven adelante y se asegure su continuidad. De esta manera, global y local no son ámbitos cerrados ni estáticos, es decir que no son entidades fijas sino que son continuamente reconfiguradas por las acciones sociales. Al mismo tiempo, acciones provenientes de sujetos situados a nivel local pueden reconfigurar los ámbitos globales y viceversa; es decir que, además de las acciones propias que configuran a cada uno de ellos, el cruce entre distintos niveles, también los recrea (HEROD, 2003). El movimiento de un nivel a otro -en términos de Kevin Cox (1998), el "salto de escalas"- implica el desarrollo de redes de asociación que se consustancian en la constitución de ciertos "lugares"1. Esto permite considerar no sólo cómo una firma u organización política puede convertirse en global para vincularse a actores y oportunidades que no se presentan a nivel local, sino también entender cómo un actor global -como una corporación transnacionalpuede buscar tornase local a partir de atraer los gustos de los consumidores en distintos lugares o reflejar los valores particulares de las comunidades (HEROD, 2003).

Nuestro trabajo está centrado, en particular, en la constitución de objetos y lugares como Patrimonio de la Humanidad, una figura que ha implementado la UNESCO, el principal organismo que interviene en los procesos de patrimonialización a nivel mundial. Las primeras acciones en este sentido se remontan a la década de 1960, en relación con el rescate de lugares y construcciones amenazadas por cuestiones tecnológicas o naturales: la relocalización de monumentos arqueológicos en Nubia ante la construcción de la represa de Aswan, la restauración de la ciudad de Florencia luego de inundaciones y los esfuerzos por combatir las crecientes invernales en Venecia (POCOCK, 1997). Frente a éstas y otras iniciativas, la UNESCO establece en 1972 la Convención para la Protección del Patrimonio Natural y Cultural Mundial e implementa el Comité para el Patrimonio Mundial, un organismo encargado de definir y proclamar la lista de bienes patrimonializables, propuestos o nominados por los diferentes países. 
Redes escalares en la construcción de los patrimonios de la humanidad.

¿Qué significa que un objeto o lugar se constituya en Patrimonio de la Humanidad? El concepto de Patrimonio de la Humanidad contiene una apelación hacia la existencia de valores universales, comunes a todos los habitantes del mundo; se trataría, según GRAHAM, ASHWORTH y TUNBRIDGE (2000), de un concepto desde el cual promover y consolidar la igualdad, el uso óptimo de los recursos naturales y culturales escasos o excepcionales y la coexistencia pacífica a nivel mundial. Conlleva, asimismo, un enfrentamiento al "extremismo chauvinista de la glorificación de los patrimonios nacionales", tal como fue el caso de la Alemania nazi. De hecho, estas cuestiones comienzan a ser discutidas con posterioridad a la Segunda Guerra Mundial, en el marco de la expansión de instituciones globales y de carácter supranacional; en particular, las Naciones Unidas y su agencia, la UNESCO, habrían creado el concepto de patrimonio global como un elemento importante para contribuir a defender y consolidar valores universales y, desde allí, la seguridad internacional (GRAHAM, ASHWORTH y TUNBRIDGE, 2000).

Actualmente se observa que la catalogación de objetos y lugares dentro de la categoría Patrimonio de la Humanidad permite su "salto" de la escala local a la global y su incorporación al circuito mundial. En realidad, el interés de los agentes locales o de las autoridades estatales porque ciertos objetos 0 lugares entren a formar parte del patrimonio mundial puede considerarse un legado de otro tipo de acciones semejantes llevadas adelante en el siglo XIX y principios del XX. De hecho, el envío de libros, mapas, pinturas y otras obras intelectuales o artísticas a las Exposiciones Universales tenían como objetivo situar a las sociedades extraeuropeas en el marco del mundo "civilizado" y atraer las inversiones extranjeras, entre otros (MALOSETTI, 2000; LOIS y ZUSMAN, 2004). En el contexto actual, algunos estudios consideran que la competencia por la patrimonialización de los lugares se asocia a un interés de las elites dirigentes por situar a éstos en el mapa cultural actual y promover su mercantilización a través de la práctica turística. Así, a partir de su sacralización en el imaginario turístico (MINCA, 2003) se legitiman los mecanismos puestos en juego para incentivar la explotación económica a nivel mundial (BOSQUE MAUREL, 1996).

Por eso, nuestro objetivo central es indagar cómo sujetos, intereses y prácticas se articulan en la constitución de redes escalares orientadas a constituir un lugar o sitio patrimonial. Para reflexionar y avanzar sobre esta cuestión se utiliza como referente empírico el reciente proceso de patrimonialización de la Quebrada de Humahuaca (provincia de Jujuy, Argentina).

El trabajo se divide en cuatro partes. En la primera presentamos los criterios tomados en cuenta para fundamentar la constitución de la Quebrada de Humahuaca como Patrimonio de la Humanidad. En la segunda, discutimos la forma en que, desde el nivel global, se conforman los valores y prácticas que participan en la construcción de los objetos y lugares como Patrimonio de la Humanidad. En la tercera, se presentan las prácticas locales desplegadas para que los objetos y lugares entren en la competencia mundial por la patrimonialización. Finalmente, en la cuarta parte analizamos el proceso de negociación entre ambos niveles y algunas limitaciones político-sociales de este tipo de estrategia económico-cultural.

\section{La Quebrada de Humahuaca, Patrimonio de la Humanidad}

En el mes de julio de 2003 la Quebrada de Humahuaca fue declarada por la UNESCO como Patrimonio de la Humanidad. Se trata de un lugar de fuerte heterogeneidad natural y de antiguo poblamiento, situado en el extremo noroeste de la Argentina. Comprende una depresión de $120 \mathrm{~km}$ de longitud, con orientación norte-sur, ubicada en el sector oriental de la Cordillera de Los Andes; se caracteriza, además, por una gran variación altitudinal (de 3.400 a 1.600 msnm) que deriva -junto a otros factores- en características 
climáticas contrastantes: áridas, en el centro y el norte del área, y subtropicales, en el sur (REBORATTI y otros, 2003).

El poblamiento del lugar está datado en torno a los 11.000 años de antigüedad, en relación con vestigios de grupos indígenas cazadores-recolectores. Desde entonces, diferentes tipos y estrategias de ocupación y aprovechamiento del lugar han producido diversas "huellas", tanto materiales como simbólicas; es el caso, por ejemplo, de la ocupación incaica del área (llevada a cabo en el siglo XV), la colonización española (entre los siglos XVI y XIX) y el proceso de integración nacional (expresado tanto en las luchas independentistas como en los diferentes proyectos económicos, como la minería, el ferrocarril y las agroindustrias, entre otros). Actualmente en la Quebrada residen cerca de 29 mil habitantes, la mayor parte de los cuales viven en localidades situadas a las márgenes del río Grande de Jujuy. A pesar del incremento de las actividades asociadas al sector terciario (fundamentalmente en las diversas dependencias gubernamentales), la principal ocupación de la población siguen siendo las actividades agrarias, sobre todo la agricultura bajo riego practicada en el fondo del valle; el turismo, si bien no es una actividad nueva en el área, está adquiriendo en los últimos años una gran importancia, bajo una modalidad de tipo itinerante o de recorrido que articula diferentes destinos del Noroeste argentino.

La Quebrada de Humahuaca fue incluida como Patrimonio de la Humanidad bajo la categoría paisaje cultural, una síntesis de la interacción entre un sistema geoecológico representativo de la región andina y las culturas que en él se asentaron durante los últimos diez mil años y que interactúan en la actualidad:

"En la Quebrada de Humahuaca, Ia interacción entre el sistema natural y las sociedades y culturas andinas se ha dado en forma continua a lo largo de más de diez mil años. (...) En la Quebrada la larga ocupación humana se encuentra testimoniada por la presencia de un amplio y diverso espectro de sitios arqueológicos e históricos -desde cazadores-recolectores hasta hispano indígenas y desde coloniales hasta republicanos.

La continuidad temporal, combinada con la concentración espacial, han dado como resultado un paisaje caracterizado por una rica densidad de componentes. Estos testimonian diversas etapas y momentos de ocupación humana del territorio, modalidades de producción del paisaje, tecnologías, estilos constructivos, ideas, conocimientos y creencias. Sobre un espacio natural rico y diverso en geoformas, fenómenos hídricos y formaciones vegetales, se articulan manifestaciones culturales de diversos orígenes -prehispánicos, hispánicos, criollos y contemporáneosamalgamadas a lo largo de los siglos por la constante circulación de bienes y personas" (PROVINCIA DE JUJUY, 2002: 271).

Como vemos en la cita anterior, se destaca la presencia de testimonios tangibles de diferentes culturas, con una alta concentración espacial; ello permitiría, se afirma en ese mismo documento, "una lectura plural de la historia y la cultura universal" (op. cit.: 5).

Con posterioridad al evento, se expusieron diferentes argumentos en torno a los efectos de la declaración de la Quebrada como sitio patrimonial. Entre ellos se destacan la preservación de la herencia indígena y, fundamentalmente, la posibilidad de promover el desarrollo local y así reducir la marginación y pobreza de la población del área; en particular, las principales autoridades provinciales y nacionales plantearon que la declaración como sitio patrimonial provocaría una expansión de la actividad turística en el área y ésta, el desarrollo local.

El paisaje, en tanto criterio de definición de un sitio de patrimonio mundial, es reconocido en muchos de los documentos elaborados por la UNESCO a partir de 1992, año en que "el Comité de Patrimonio Mundial adoptó las revisiones a los criterios culturales de la Guía Operativa para la Implementación de la 
Redes escalares en la construcción de los patrimonios de la humanidad.

Convención del Patrimonio Mundial e incorporó la categoría de paisajes culturales" (RÖSSLER, 1998). Este concepto buscaría dar cuenta de la interacción entre el trabajo del hombre y la naturaleza (artículo 1 de la Convención). Dentro de la tipología de paisajes reconocida por la Guía Operativa, la Quebrada de Humahuaca sería considerada "un paisaje evolutivo (u orgánicamente desarrollados) resultante de condiciones sociales, económicas, administrativas, y/o religiosos, que se han desarrollado conjuntamente y en respuesta $a$ su medio ambiental natural (...) continuo en el tiempo, que sigue teniendo un papel social activo en la sociedad contemporánea, conjuntamente con la forma tradicional de vida" (RÖSSLER, 1998 ).

En realidad, los documentos elaborados con el fin de lograr la patrimonialización de la Quebrada hablan de itinerario cultural, considerado por Rössler "un tipo cultural y dinámico de paisaje cultural" que contemplaría el movimiento y el intercambio entre culturas en el espacio y el tiempo. Sin embargo, el reconocimiento de la Quebrada como paisaje y no como itinerario habla del triunfo del criterio de no homologar ambos conceptos. De hecho, se prefirió reconocer a la Quebrada como paisaje cultural ya que se considera que dicho sitio sería un tramo de un itinerario, el camino del Inca, que abarca a otros países de la región y que va desde Córdoba al Alto Perú" (CLARÍN, 2-072003. "La Quebrada de Humahuaca fue declarada Patrimonio Cultural y Natural de la Humanidad").

Más allá del debate por su reconocimiento como paisaje o itinerario y sobre la diferenciación conceptual entre esos términos ${ }^{2}$, ambos acaban construyendo un tipo específico de lugar, en tanto orientan las lecturas, interpretaciones, miradas, experiencias de los distintos actores que intervienen e intervendrán en la Quebrada. El pretendido sentido universalizador y plural reduce, en realidad, las posibilidades que la Quebrada podría ofrecer sin dicha catalogación. Desde el punto de vista estrictamente turístico, las acciones vinculadas a la patrimonialización acaban orientando tanto las prácticas materiales como representacionales a la construcción de un parque temático. La Quebrada se fosiliza, se eterniza en el espacio y tiempo (MINCA, 2003), a la vez que el visitante entra en un mundo de fantasía, alejado de la realidad, sin conflictos. El turista se deja llevar por las narrativas que guían la visita de este paisaje o itinerario. El control del paisaje o itinerario por parte de aquellos actores responsables de la materialización de la propuesta de patrimonialización y preservación (autoridades locales, promotores turísticos, industria hotelera) lleva a que el "factor sorpresa" esté dirigido o pautado por la mirada y la experiencia turísticas ${ }^{3}$. De lo dicho hasta aquí podría derivarse que la modalidad de parque temático es la forma en que en los "lugares" se internalizan aquellos valores universales y las conceptualizaciones asociadas.

\section{Las prácticas globales se tornan locales}

En las ideas discutidas en el ítem anterior subyacen las siguientes preguntas: ¿cómo se define qué es pasible de ser considerado patrimonio global?, ¿quiénes y desde dónde lo definen?. Según GRAHAM, B., G. ASHWORTH y J. TUNBRIDGE una de las principales contradicciones que se observa al respecto es que, "dada la extensión de las desigualdades globales actuales, el patrimonio global, incluyendo aquel localizado en regiones donde la preservación del patrimonio no es una alta prioridad, es definido de hecho por los ciudadanos de las regiones más ricas y no tanto por las poblaciones indígenas" (GRAHAM, B., G. ASHWORTH y J. TUNBRIDGE: 239).

En estos treinta años de implementación de Ia Convención de la UNESCO para la Protección del Patrimonio Natural y Cultural Mundial se ha avanzado en la ampliación de los criterios de inclusión y en la implementación de mecanismos más descentralizados. En los últimos años, la categoría de sitio ha incorporado el concepto de itinerario cultural. Como decíamos 
antes, la inclusión de esta noción "se fundamenta en la dinámica del movimiento y en la idea de intercambio con continuidad en el espacio y en el tiempo (...), se refiere a un conjunto de valor superior a la suma de los elementos que le constituyen y que le confiere sentido" (ICOMOS, 1994, cfr Provincia de Jujuy, 2002: 17) ${ }^{4}$. Si bien la idea de itinerario supone la superación de las limitaciones de las conceptualizaciones usadas hasta ese momento, su construcción no deja de ser un síntoma más de las prácticas económicas culturales recientes. La patrimonialización a través del rescate de la idea de itinerario no puede desligarse del propio proceso de globalización, la redefinición de los lugares y las prácticas que éste implica. En este contexto, la idea de flujos predomina sobre la de lugares (cerrados); las prácticas en red toman preeminencia sobre aquellas de carácter contiguo. Justamente esta concepción es la que ha permitido revalorizar, en la Quebrada de Humahuaca, muchas de las prácticas del pasado basadas en la circulación y que legitiman la patrimonialización como itinerario (corredor de intercambios interétnicos, arreo de ganado al Potosí, tendido del ferrocarril a Bolivia, etc.). Por otro lado, a través de este tipo de patrimonialización se ha potenciado el turismo, una de las actividades globales en las que ha tenido un efecto directo el aumento de los flujos a partir del abaratamiento de los costos de transporte. Es esta práctica la que también contribuye a resignificar los lugares, construidos ahora como atractivos a partir de su patrimonialización.

Entonces, es posible reconocer que a través del turismo una persona o un conjunto de personas se ponen en contacto con elementos patrimonializados que tienen la capacidad de evocar y condensar significados. Pero también es a través de la práctica turística que el patrimonio entra en el mercado para ser consumido (pues dicha práctica lo convierte en una mercadería), adaptándose a las nuevas demandas y necesidades. A su vez, podríamos decir que la construcción del patrimonio como atractivo se presentaría como una estrategia de legitimación cultural de la práctica turística. De este modo, lo que en un principio aparece como dos esferas separadas e independientes (el turismo por un lado, el patrimonio por otro), pueden verse como profundamente entrelazadas: el patrimonio se comercializa a través del turismo, y el turismo adquiere legitimidad cultural a través del patrimonio. Se observa, así, una asociación que tiende a difundirse cada vez más: la que se establece entre los dominios de la cultura y la economía (BERTONCELLO, CASTRO, ZUSMAN, 2003b).

Sin embargo, aún persisten algunas contradicciones, como la que existe entre el incremento del turismo y la preservación del valor patrimonial. Se argumenta que el incremento del turismo, tanto el manifiesto como el "latente" ${ }^{\prime \prime}$, expresa un interés y una demanda global sobre este "patrimonio universal". Pero, al mismo tiempo, la mercantilización de los lugares patrimonializados a través del turismo conlleva una amenaza o riesgo para la preservación del valor patrimonial. Los procesos de deterioro ambiental, tales como la excesiva artificialización del medio, los conflictos culturales derivados de la coexistencia entre turistas y población local, la dependencia económica que se genera en los destinos turísticos para satisfacer las demandas de los turistas, o las deficientes condiciones de los mercados laborales turísticos, son algunos problemas derivados de la integración de estos lugares a los circuitos turísticos (BERTONCELLO, CASTRO, ZUSMAN, 2003 a).

\section{Las prácticas locales se tornan globales}

Si bien las directivas y procedimientos que se siguen para la patrimonialización de lugares y objetos son globales, en este caso definidas por el Comité de la UNESCO, los gobiernos locales (nacional, provincial, municipales) que actuaron a fin de conseguir la patrimonialización, retoman y reinterpretan esas pautas; de hecho, algunos autores visualizan estos procesos como una posibilidad de 
Redes escalares en la construcción de los patrimonios de la humanidad.

construcción de poder a nivel local. De hecho, son las municipalidades las que, a partir del partir de la patrimonialización, "salen" en búsqueda de inversiones en materia hotelera y de infraestructura; a raíz de ello, algunos estudios interpretan esta búsqueda como ventanas de oportunidad para el fortalecimiento del poder local (local empowerment).

En el caso de la propuesta de inclusión de la Quebrada de Humahuaca como Patrimonio de la Humanidad se observa una selección de criterios normativos de la Convención de Patrimonio Mundial (1972) y una elaboración de argumentaciones ad-hoc, que finalmente construyen un sentido de lugar.

En particular, se destacan una serie de rasgos para la nominación, entre los que se priorizan:

"ser la manifestación de un intercambio considerable de valores humanos durante un determinado período o en un área cultural específica, en el desarrollo de la arquitectura, las artes monumentales, la planificación urbana o el diseño paisajístico" (criterio ii);

"constituir un ejemplo sobresaliente de hábitat o establecimiento humano tradicional o del uso de la tierra, que sea representativo de una cultura o culturas, especialmente si se han vuelto vulnerables por efectos de cambios irreversibles" (criterio v).

Tal selección se argumenta, como vimos anteriormente, con la idea de corredor natural en el que vivieron y circularon diferentes sociedades y culturas a lo largo de los últimos 10 mil años; "la Quebrada de Humahuaca ha funcionado como permanente vía de interacción longitudinal y transversal, vinculando territorios y culturas distantes y diferentes, desde el Atlántico al Pacífico y desde los Andes a las llanuras meridionales" (PROVINCIA DE JUJUY, 2002: 5). Desde esta idea de corredor natural e histórico se argumenta la "autenticidad" patrimonial del lugar y el documento elaborado por la provincia de Jujuy propone su nominación como Itinerario cultural. Son estos rasgos que constituirían las marcas de distinción de la Quebrada; el poder del capital simbólico colectivo que se presenta para el capital como renta monopólica (HARVEY, 2002). En efecto, Harvey destaca que el capital busca localizarse en estos lugares ya que, frente a la pérdida de otros poderes monopólicos a partir de la disminución de los costos de transporte y de comunicación y de la reducción de las barreras comerciales, la puja por el capital simbólico colectivo se torna en la base más importante de las rentas monopólicas. En este caso, la unicidad, autenticidad y particularidad de la Quebrada resultan vitales para la industria hotelera, del transporte aéreo y el turismo.

A través del proceso de patrimonialización, y según la Secretaria de Cultura y Turismo de la Provincia de Jujuy, Liliana Fellner, la Quebrada en sí misma se torna una marca, un $\log ^{6}$ :

"La quebrada, luego de ser declarada patrimonio mundial, tiene que funcionar como una marca. Esto quiere decir que, por ejemplo, la carne de llama producida en la zona se puede exportar con la especificación de origen. Lo mismo con las artesanías. Y lo mismo con gran cantidad de productos. Ahora tenemos la llave; tenemos que saber como abrir la puerta" (JUJUY AL DÍA, 4-07-03- "La Quebrada tiene que ser una marca, con esta inclusión en la lista de la UNESCO nos dieron una llave, ahora tenemos que saber abrir la puerta")

¿Ahora bien, a escala local, quiénes
participan de este proceso de
patrimonialización? Según la narrativa oficial, las
acciones para la nominación de la Quebrada se
iniciaron en el año 1986, a partir de una reunión
realizada en la localidad de Tilcara entre "el
Intendente de Humahuaca, los Comisionados
Municipales de Huacalera y Purmamarca, las
autoridades policiales, representantes de
extensión INTA de Hornillos, del Centro de
Nutrición 1 de Huasamayo, del Colegio Nacional
de Tilcara y dos diputados nacionales con el
representante de Argentina ante el Comité de
Patrimonio Mundial de la UNESCO"; allí se


comprometieron a emprender acciones conducentes a lograr la declaración de la Quebrada como Patrimonio Mundial (Provincia de Jujuy, 2002: 256). Es bastante elocuente que entre quienes participaron estén ausentes, por ejemplo, representantes indígenas, aunque vale aclarar que en ese momento prácticamente no existían movimientos organizados. Estas inquietudes son retomadas por el gobierno provincial recién en el año 2000, quien encomienda un estudio de factibilidad al Consejo Federal de Inversiones; ello ocurre ante la posibilidad de construcción de un electroducto por el fondo de la quebrada. Desde la narrativa oficial el movimiento de reacción frente al proyecto de la red energética creó una conciencia sobre la necesidad de preservar el paisaje del lugar. Según el propio gobernador Fellner:

"En el año 2000 decidí la instalación de una línea de alta tensión en la Quebrada y los habitantes respondieron con una pueblada. Dijeron que la obra destruiría el sitio. Y entonces nosotros tomamos conciencia de lo que teníamos en mano. Nos dimos cuenta de que teníamos algo de mucho valor" (JUJUY AL DÍA 06-07-03 "Si trabajamos bien, acabaremos con el desempleo en la Quebrada, Entrevista al Gobernador Fellner).

Desde el punto de vista de otros protagonistas, se trataba de dos proyectos concomitantes pensados para el área. Cabe destacar que la energía del electroducto sería vendida a Bolivia y no contemplaba ofrecer este tipo de servicio a la población local. Se entiende entonces, la reacción local frente a este último proyecto y el hecho que la patrimonialización de la Quebrada contara con mayor consenso social.

Cabe destacar, finalmente, que las gestiones para la patrimonialización estuvieron a cargo de distintas áreas de la Secretaría de Turismo, Secretaria de Cultura, Cancillería de la Nación y el Gobierno de Jujuy (Dirección de Prensa -Senado de la Nación, 2 de julio del 2003), proceso que finalizó con la postulación oficial mediante una carta dirigida por el entonces presidente Eduardo Duhalde al director del Centro de Patrimonio Mundial de la UNESCO, Francisco Bandarín (Clarín, 02 de julio de 2003, "La Quebrada de Humahuaca fue declarada Patrimonio Cultural y Natural de la Humanidad"). A esta articulación entre autoridades nacionales y provinciales se le suman, desde las narrativas oficiales, la participación de las comunidades aborígenes a través de talleres realizados en diferentes zonas (JUJUY AL DÍA, 6-07-2003. "Si trabajamos bien, acabaremos con el desempleo en la Quebrada" Entrevista al Gobernador Fellner).

Si bien la preocupación por la preservación del patrimonio aparece como global, "en la práctica el 'patrimonio mundial' es protegido y administrado por gobiernos municipales /provinciales/ nacionales, y no por la comunidad internacional" (GRAHAM, ASHWORTH Y TUNBRIDGE, 2000: 238). En este sentido son elocuentes las declaraciones de la Subsecretaria de Cultura de la Nación, Magdalena Faillace, quien afirma que "la designación de la Quebrada de Humahuaca como Patrimonio Mundial no significa que la UNESCO va a otorgar fondos para su cuidado. Esta distinción constituye un compromiso que asume el gobierno nacional, que ahora deberá cuidar este paisaje que es patrimonio de toda la humanidad" (La Nación, 03 de julio de 2003, "Humahuaca, patrimonio mundial"). En particular, el gobierno se compromete a cumplir con un plan en el que se prevé, en una primera etapa, la realización de obras de infraestructura que permitan solucionar los principales factores de riesgo y lograr una óptima puesta en valor de los bienes del área, así como la promoción de tareas de formación y capacitación de equipos técnicos locales y la comunicación e investigación sobre los valores del patrimonio de la Quebrada.

La convivencia entre la puesta en juego de un proyecto de patrimonialización que partió de los valores culturales emergentes de la UNESCO y el requerimiento de que, una vez patrimonializado, las acciones de desarrollo y preservación frente al deterioro quede en 
Redes escalares en la construcción de los patrimonios de la humanidad.

manos locales trae a la luz la pregunta ¿de quién es la Quebrada de Humahuaca: de la provincia de Jujuy, del gobierno nacional o es realmente un patrimonio de la humanidad? De hecho ciertos actores situados en la propia quebrada de Humahuaca discuten la injerencia nacional sobre un bien que consideran que, desde el punto de vista de los mismos, debería ser administrado localmente y que los beneficios de la explotación deberían quedar en la misma Quebrada.

\section{Conclusiones}

En este trabajo hemos analizado las relaciones escalares tejidas por distintos agentes, prácticas e intereses a fin de obtener la nominación de la Quebrada de Humahuaca como Patrimonio de la Humanidad.

Hemos visto que los valores y
conceptualizaciones elaboradas por especialistas que participan directamente en la UNESCO y organismos asociados (ICOMOS) son presentados como universales, y son internalizados por las elites culturales y dirigentes locales (municipales, provinciales, nacionales) a fin de preparar la documentación y realizar las gestiones para la nominación. La adecuación de la propuesta presentada por la actuación local, a partir de caratular a la Quebrada como itinerario y de mostrar sus rasgos de excepcionalidad, es legitimada con la incorporación de este sitio dentro del conjunto de componentes que la UNESCO reconoce como parte del patrimonio mundial.

Este reconocimiento, a manera de rito de pasaje, abre el camino para el ingreso de la Quebrada al mundo internacional de la industria turística. En relación con la patrimonialización, los gobiernos municipales, provinciales -también el nacional- ponen en marcha el mecanismo de crear la "marca" Quebrada, a fin de mostrar las potencialidades que ésta ofrece al capital para producir rentas monopólicas. Se espera que esta estrategia de mercantilización de los componentes naturales-histórico-culturales del "lugar" permita superar los problemas de pobreza que afectan hoy al área y tengan efectos multiplicadores sobre el resto de la provincia de Jujuy.

Esta estrategia económico-cultural que, supuestamente, tendrá efectos positivos sobre todas las clases sociales presenta algunos aspectos opacos que deseamos señalar. En primera lugar, nos cuestionamos el carácter universal de la forma de construir los valores y conceptualizaciones a patrimonializar. Así, el concepto de paisaje cultural, elaborado por un grupo de expertos, apenas contempla los valores que la comunidad asigna a los paisajes culturales (MUJICA BARREDA, 1998). Esta observación ya ha sido señalada en el encuentro de Paisajes Culturales en los Países Andinos (1998); quizás la incorporación de la percepción de las comunidades locales podría multiplicar las miradas que participan en la definición de los criterios de patrimonialización y no limitarlas a las visiones del mundo de un grupo de especialistas.

En segundo lugar, observamos una distancia entre la propuesta de congelar la imagen de una sociedad plural con aquella otra que se experimenta en la vida cotidiana de la propia Quebrada, contexto en el que la discriminación y jerarquización étnica se hacen continuamente presentes. Más allá de la participación de las comunidades indígenas en la elaboración de la propuesta de nominación, dudamos que la inserción en las actividades derivadas de la industria turística por parte de la población que habita en la Quebrada, tal como anuncian algunas autoridades ${ }^{7}$, permita modificar la situación de exclusión económicocultural que permea a la sociedad local.

1 En este trabajo se usa el término lugar, sin comillas, como ámbito geográfico significativo de referencia empírica. Cuando el término aparece entrecomillado, adquiere el sentido otorgado por Agnew (1987): localización, distribución espacial, sentido adquirido por las interacciones sociales co- 


\section{Notas}

tidianas y vivencias de los sujetos que lo habitan.

2 En el Congreso Internacional de Itinerarios Culturales del ICOMOS realizado en Navarra en el año 2001 se reconoce la diferenciación entre ambos conceptos. "Los itinerarios culturales se caracterizan por su movilidad y entrañan una dinámica espacial e intangible de ida y vuelta que no posee el paisaje cultural., el cual obedece a un criterio más estático y restringido, aunque también posea caracteres evolutivos. El itinerario cultural normalmente abarca numerosos paisajes culturales diversos entre sí. Un paisaje cultural no es dinámico en un contexto geográfico tan vasto como el que potencialmente puede abarcar un itinerario cultural. El itinerario cultural puede haber generado y seguir generando paisajes culturales. Pero esto no sucede a la inversa". (SUÁREZ-INCLÁN, 2002).

3 La idea de nostalgia imbuida en la parquetematización no toma en cuenta que la patrimonialización es una intervención actual sobre el "lugar" y que son las miradas actuales las que se dirigen hacia el pasado para orientar los aspectos a preservar. En síntesis, la propia idea de preservación presente en la construcción del patrimonio implica una modificación del lugar.

${ }^{4}$ La idea de itinerario fue trabajada en sucesivas reuniones organizadas por la UNESCO y el Comité Científico Internacional de Itinerarios del ICOMOS, en especial las de Madrid (1994), Tenerife (1998) y Pamplona (2001).

5 Es decir, el turismo practicado por aquellos que consumen libros o guías de viaje sobre estos lugares.

6 Antes de la patrimonialización de la Quebrada, la provincia de Jujuy en su plan de desarrollo turístico apostaba a hacer de la provincia una marca de distinción. Así, dicho plan habla acerca de la necesidad de consolidar un concepto explícito y consensuado del destino turístico 'Jujuy', como eje para la definición de productos turísticos, su promoción y comercialización. Ese concepto o "marca" se define de la siguiente manera: Jujuy es "un destino turístico en que la diversidad y contraste de paisajes sirven de marco a prácticas culturales milenarias pero vigentes" (Tomo II, pág. 18). A partir de la patrimonialización de la Quebrada podemos suponer dos escenarios posibles. En el primero, la marca Quebrada superará a la marca Jujuy (es decir, la quebrada pasará a ser un lugar en el imaginario global, al estilo de la marca Patagonia); el segundo escenario supone que la marca Quebrada provocará un efecto derrame sobre otros sitios turísticos provinciales o regionales.

7 JUJUY AL DÍA, 06-07-03, "Si trabajamos bien, acabaremos con el desempleo en la Quebrada".

\section{Bilbiografia}

AGNEW, J. Place and Politics: The geographical mediation of state and society. London: Allen \& Unwin, 1987.

BALLART HERNÁNDEZ, J., J JUAN I TRESSERRAS .. Gestión del patrimonio cultural. Barcelona: Ariel Turismo, 2001.

BERTONCELLO, R., H. CASTRO y P. ZUSMAN: "Turismo y patrimonio en Argentina. Hacia una conceptualización desde las Geografías Culturales". En: UNIÓN GEOGRÁFICA INTERNACIONAL. Encontro as Dimensoes históricas da relaçao entre espaço e cultura. Actas en CD, Rio de Janeiro, 2003a.

BERTONCELLO, R., H. CASTRO y P. ZUSMAN: "Turismo y patrimonio: una relación puesta en cuestión". En: BERTONCELLO, R. y A. F. ALESSANDRI CARLOS (comp.): Procesos territoriales en Argentina y Brasil, Buenos Aires: Facultad de Filosofía y Letras (UBA) - USP, 2003b, pp 277-291

BOSQUE MAUREL, J.: "O patrimônio da humanidade". En: YAZIGUI, E. (org) Turismo: espaço, paisagem e cultura. Sao Paulo: Editora Hucitec, 1996, pp 77-87.

COX, K.: "Spaces of dependence, spaces of 
Redes escalares en la construcción de los patrimonios de la humanidad.

engagement and the politics of scale, or looking for bcalpolitics". PolticalGeography Vol 17 (1), 1998, pp. 1-23.

GARCÍA CANCLINI, N.: "Los usos sociales del patrimonio Cultural" En: AGUILAR CRIADO, E. Patrimonio Etnológico. Nuevas perspectivas de estudio. Sevilla: Consejería de Cultura. Junta de Andalucía, 1999, pp. 16-33.

GRAHAM, B., G. ASHWORTH y J. TUNBRIDGE: A Geography of Heritage. Power, culture and economy. London: Arnold, Oxford University Press, 2000.

HARVEY, D.: "The art of rent: globalization, monopoly and the commodification of culture". En: PANITCH, L. y C. LEYS (eds.): A World of Contradictions. Socialist Register http:// www.yorku.ca/socreg/, 2002.

HEROD, A.: "Scale: The local and the Global" En: HOLLOWAY, S.L., RICE, S. P., VALENTINE, G. (eds). Key concepts in Geography, London: Sage Publications, 2003, pp. 229-247.

LOIS, C. y P. ZUSMAN: "Geografía y política en el proceso de consolidación del Estado argentino: estrategias científico-culturales de reconocimiento político-internacional". En: VI Congreso Latinoamericano de Historia de la Ciencia y la Tecnología, Buenos Aires (mimeo), 2004

MALOSETTI COSTA, L.: Los primeros modernos. Arte y Sociedad en Buenos Aires a fines del siglo XIX. Buenos Aires: Fondo de Cultura Económica, 2001.

MUJICA BARREDA, E.: "Temas para la reflexión y el diálogo a manera de conclusiones y recomendaciones sobre los paisajes culturales en los países andinos". En: MUJICA BARREDA, E. (ed.): Paisajes culturales en los Andes. UNESCO-ICOMOS. Disponible en http:// w w w. condesan./org/unesco/ paisajes culturales andes.htm (fecha de consulta, 20 de marzo del 2004) (1998).

MINCA, C.: "Re-inventing the 'square": postcolonial geographies and the tourist gaze in Jamaa el Fna, Marrakech". En: MINCA y OAKES (eds.), Travels in Paradox. Remapping Tourism. Boulder, CO: Rowman \& Littlefield, 2003.

NIGRO, C.: "Patrimônio cultural e território urbano", Boletim Paulista de Geografia, № 78, 2002, pp. 45-76.

PRAT, LI.: "El concepto de patrimonio cultural". Política y Sociedad, 27, 1998, pp. 63-76.

SCIFONI, S.: "Patrimônio mundial: Do ideal humanista à utopia de uma nova civilizaçao". GEOUSP. Espaço e Tempo, No 14, 2003, pp. 7788.

SUÁREZ INCLAN, M. R.: Comité internacional de Itinerarios Culturales (CIIC). Reunión Científica sobre La independencia conceptual y sustantiva de los itinerarios culturales respecto a los paisajes culturales. Disponible en http:// www.esicomos.org/Nueva carpeta/ CIIC esp.htm. Fecha de consulta 20 de marzo del 2004. (2002)

POCOCK, D. "Some reflections on World Heritage", Area 29, 1997, pp. 260-268.

PROVINCIA DE JUJUY: Quebrada de Humahuaca. Provincia de Jujuy. Propuesta para la inscripción a la lista de patrimonio mundial, en http://www.jujuy.gov.ar/quebrada/ Index.htm, 2002.

PROVINCIA DE JUJUY: Plan de Desarrollo Turístico de la Provincia de Jujuy, Tomos I y II, San Salvador de Jujuy: Gobierno de la Provincia de Jujuy - Consejo Federal de Inversiones, 2001.

ROSSLER, M. "Los paisajes culturales y la convención del patrimonio mundial", en MUJICA BARREDA, E. (ed.), Paisajes culturales en los Andes. UNESCO-ICOMOS. Disponible en http:// w w w. condesan.org/une sco/ paisajes culturales andes.htm (fecha de consulta, 20 de marzo del 2004), (1998)

REBORATTI, C., J. C. GARCÍA CODRÓN, M. ALBECK, H. CASTRO y M. ARZENO: "Una visión general de la Quebrada". En: REBORATTI., C. (coord.): La Quebrada. Buenos Aires: Editorial La Colmena, 2003, pp. 17-46. 
UNESCO: Lista del Patrimonio Mundial, disponible en http://www.unesco.patrimonio (fecha de consulta: 15 de abril de 2004).

\section{Artículos periodísticos:}

JUJUY AL DÍA, 04-07-03- "La Quebrada tiene que ser una marca, con esta inclusión en la lista de la UNESCO nos dieron una llave, ahora tenemos que saber abrir la puerta" Entrevista a la Secretaria de Cultura y Turismo de la provincia de Jujuy Liliana Fellner.

JUJUY AL DÍA, 06-07-2003. "Si trabajamos bien, acabaremos con el desempleo en la Quebrada" Entrevista al Gobernador Fellner.

CLARÍN, 02 de julio de 2003, "La Quebrada de Humahuaca fue declarada Patrimonio Cultural y Natural de la Humanidad".

LA NACIÓN, 03 de julio de 2003, "Humahuaca, patrimonio mundial"

Trabalho enviado em agosto de 2006

Trabalho aceito em abril de 2007 
